\title{
A community-based prospective cohort study of exclusive breastfeeding in central Nepal
}

\author{
Rajendra Karkee ${ }^{1 *}$, Andy H Lee ${ }^{2}$, Vishnu Khanal ${ }^{3}$ and Colin W Binns ${ }^{2}$
}

\begin{abstract}
Background: Existing information on breastfeeding in low income countries such as Nepal has been largely derived from cross-sectional demographic health surveys. This study investigated exclusive breastfeeding rates, and compared the duration of exclusive breastfeeding between rural and urban mothers in central Nepal using an alternate cohort methodology.

Methods: A community-based prospective cohort study was conducted among 639 recently delivered mothers representative of the Kaski district of Nepal. Breastfeeding information was obtained at birth $(n=639), 4$ weeks ( $n=639), 12$ weeks ( $n=615 ; 96.2 \%)$ and 22 weeks $(n=515 ; 80.6 \%)$ through repeated interviews using validated questionnaires. Risk of cessation of exclusive breastfeeding was assessed by Cox regression analysis.

Results: The great majority of women received breastfeeding information (74\%) and were encouraged to breastfeed by health personnel or family members (81\%). Although nearly all mothers (98\%) breastfed up to six months, the reported exclusive breastfeeding rate declined rapidly from $90.9 \%$ at birth to $29.7 \%$ at 22 weeks. Urban women experienced significantly shorter $(p=0.02)$ exclusive breastfeeding duration (mean 104.5, 95\% Cl 95.8 to 113.1 days) and were more likely to cease exclusive breastfeeding (hazard ratio (HR) 1.28, 95\% Cl 1.03 to 1.60) than their rural counterparts (mean 144.7, 95\% Cl 132.3 to 157.1 days). Breastfeeding problem (HR 2.07, 95\% Cl 1.66 to 2.57) and caesarean delivery (HR $1.88,95 \% \mathrm{Cl} 1.36$ to 2.62$)$ were also significantly associated with exclusive breastfeeding cessation.
\end{abstract}

Conclusions: Despite the almost universal practice of breastfeeding, the reported exclusive breastfeeding rates declined substantially over time. Exclusive breastfeeding up to six months was more common in rural than urban areas of central Nepal. Urban mothers also exclusively breastfed shorter than rural mothers.

Keywords: Exclusive breastfeeding, Risk factors, Nepal

\section{Background}

Appropriate infant feeding, namely, early initiation of breastfeeding with colostrum as the first food, exclusive breastfeeding to six months, followed by the introduction of complementary foods with continue breastfeeding, is important for survival as well as physical growth and mental development of the child [1-3]. Infants who are not exclusively breastfed for the first six months have high rates of mortality and morbidity, particularly those associated with diarrhoea and pneumonia [4,5]. Globally, $11.6 \%$ of child deaths in 2011 are due to suboptimal breastfeeding

\footnotetext{
* Correspondence: rkarkee@gmail.com

${ }^{1}$ School of Public Health and Community Medicine, BP Koirala Institute of Health Sciences, Dharan, Nepal

Full list of author information is available at the end of the article
}

[6]. Moreover, breastfeeding is known to have long term health benefits against non-communicable diseases [7].

Despite efforts to improve breastfeeding rates over the past two decades, including implementation of the International Code of Marketing of Breastmilk Substitutes, the Baby-Friendly Hospital Initiative, and launching of the WHO/UNICEF's Global Strategy for Infant and Young Child Feeding, the global rate of exclusive breastfeeding has remained stagnant below $40 \%[8,9]$. In South Asia, exclusive breastfeeding has increased slightly from $40 \%$ in 1995 to $45 \%$ in 2010 [10], but comparisons between surveys should be made with caution because different definitions and methodologies were used in calculating exclusive breastfeeding rates $[11,12]$. Moreover, the rate of exclusive breastfeeding for the first six 
months varies in relation to maternal and environmental factors [13-15]. A study conducted in southern Nepal, for example, found that women from hill origin exclusively breastfed longer than women residing in Terai (plain area) [16]. Higher rates of breastfeeding and exclusive breastfeeding are generally observed among lower income countries, while rural mothers usually breastfeed longer than their urban counterparts [8].

In the literature, reports on breastfeeding in Nepal were mainly derived from National Demographic Health Surveys (NDHS) [17]. The NDHS collected retrospective cross-sectional information on infant feeding in the past 24-hours from mothers who gave birth within two years preceding the survey, which could incur recall bias when assessing exclusive breastfeeding. In addition, the data, often presented as a period prevalence rate, might be difficult to interpret. Several other studies conducted in Nepal also adopted a cross-sectional design and did not cover the entire first six months of life $[18,19]$. In view of these shortcomings, a prospective cohort study of community-dwelling women was conducted to investigate exclusive breastfeeding rates, to compare the exclusive breastfeeding duration between rural and urban mothers, and to determine factors associated with early cessation of exclusive breastfeeding in central Nepal. We hypothesized that exclusive breastfeeding is different between rural and urban locations, with a higher risk of early cessation among urban women.

\section{Methods}

\section{Study setting}

Nepal is a small but diverse country in South Asia. Female literacy rate is $67 \%$ and total fertility rate is 2.6 births per women. The median age at first birth is 20.2 years. Most of the married women are occupied with home duties [20]. The location of this study was Kaski, a centrally located hills district of Nepal. The district has $75 \%$ female literacy rate and approximately 13,800 babies are born annually [21].

\section{Study design and participants}

A large community-based prospective cohort study of utilisation of maternity services was conducted between December 2011 and November 2012 in the Kaski district. Details about participants, study design and sampling procedure had been described elsewhere [22]. Briefly, a total of 701 pregnant women of 5 months or more gestational age were recruited from five urban wards and seven rural illakas of the Kaski district, and were followed up for six months after delivery. Fifteen female data enumerators, who were recruited locally, searched for and identified pregnant women in their locality with the help of female community health volunteers and health facility registrations for antenatal care visits. They then visited the pregnant women's houses.

The study was conducted according to the guidelines laid down in the Declaration of Helsinki and all procedures involving human subjects/patients were approved by the Human Research Ethics Committee of Curtin University (approval number HR 130/2011), and the Ethical Review Board of the Nepal Health Research Council (approval number 88/2011). A STROBE checklist can be found in Additional file 1. Written informed consent was obtained from all subjects. An information sheet was distributed and read to each consented subject before obtaining her signature or thumb-print. Confidentiality of the information provided was maintained throughout the study.

\section{Data collection}

The questionnaire used in the interview was adapted from the NDHS and another validated instrument on breastfeeding; see Additional file 2 [23]. It was pretested on 25 postpartum women for cultural appropriateness, content validity and understanding. Fifteen female community health volunteers, trained by the first author, conducted the baseline interviews to collect information on socio-demographic and obstetric characteristics of the pregnant women. The participants were followed up with three subsequent household visits by the same female enumerators at 4 weeks, 12 weeks and 22 weeks postpartum, respectively. Breastfeeding at birth was assessed during the second follow-up interview.

\section{Statistical analysis}

The outcome variable was the reported duration of 'exclusive breastfeeding', defined as the infant being given breastmilk only without any other feeds (aside from medications) since birth [2]. The main exposure variable of interest was residential location (rural versus urban). Table 1 lists other maternal socio-demographic and obstetric variables. Four levels of education were recorded, namely, none, primary $\left(1-5^{\text {th }}\right.$ grade $)$, secondary $\left(6-10^{\text {th }}\right.$ grade), and college (after $10^{\text {th }}$ grade). Caste was defined according to the government's classification in the health system. 'Upper caste' and 'lower caste' referred to IndoAryan people, whereas 'janajati' referred to Tibeto-Burman people and the term 'religious minorities' denoted people who are Muslim or Christian. In this study, only three women belonged to the religious minority so they were merged with the janajati group. Employment status was categorised as employed (full-time salaried job), semiemployed (wage based labour, small business or employed abroad), and unemployed (agricultural, housewife or nothing). Breastfeeding information was recorded yes if the woman had reported receiving any breastfeeding education or information from anywhere on how to feed her baby. 
Table 1 Maternal characteristics by residential location, Kaski District, Nepal ( $n=639$ )

\begin{tabular}{lcccc}
\hline Characteristic & $\begin{array}{c}\text { Urban } \\
\mathbf{n}(\%)\end{array}$ & $\begin{array}{c}\text { Rural } \\
\mathbf{n}(\%)\end{array}$ & $\begin{array}{c}\text { Total } \\
\mathbf{n}(\%)\end{array}$ & $\mathbf{p}^{*}$ \\
\hline $343(53.7)$ & $296(46.3)$ & 639
\end{tabular}

Parity

Primiparous

Multiparous

Employment status

Unemployed

Semi-employed

Employed

Caste

Upper caste

Janajati

Lower caste

Education

None

Primary

Secondary

College

Place of delivery

Home

Facility

Method of delivery

Vaginal

Caesarean

Frequency of antenatal visits

$<4$

$\geq 4$

Breastfeeding information

Yes

No

Encouragement to breastfeed

Yes

No

Sex of infant

Male

Female

Breastfeeding problem

No

Yes
0.07

$170(49.6) \quad 159(53.7) \quad 329(51.5)$

$173(50.4) \quad 137(46.3) \quad 310(48.5)$

$<0.001$

$249(72.6) \quad 260(87.8) \quad 509(79.7)$

$71(20.7) \quad 27(9.1) \quad 98(15.3)$

$23(6.7) \quad 9(3.0) \quad 32(5.0)$

$171(50.3) \quad 168(56.8) \quad 339(53.3)$

$97(28.5) \quad 41(13.9) \quad 138(21.7)$

$72(21.2) \quad 87(29.4) \quad 159(25.0)$

$31(9.0) \quad 22(7.4) \quad 53(8.3)$

$72(21.0) \quad 61(20.6) \quad 133(20.8)$

$96(28.0) \quad 142(48.0) \quad 238(37.2)$

$144(42.0) \quad 71(24.0) \quad 215(33.6)$

$29(8.5) \quad 63(21.4) \quad 92(14.5)$

$311(91.5) \quad 231(78.6) \quad 542(85.5)$

$277(81.2) \quad 273(92.9) \quad 550(86.6)$

$64(18.8) \quad 21(7.1) \quad 85(13.4)$

$92(26.8) \quad 75(25.3) \quad 167(26.1)$

$251(73.2) \quad 221(74.7) \quad 472(73.9)$

$<0.001$

$212(61.8) \quad 258(87.2) \quad 470(73.6)$

$131(38.2) \quad 38(12.8) \quad 169(26.4)$

$271(79.0) \quad 245(82.8) \quad 516(80.8)$

$72(21.0) \quad 51(17.2) \quad 123(19.2)$

$206(60.1) \quad 172(58.1) \quad 378(59.2)$

$137(39.9) \quad 124(41.9) \quad 261(40.8)$

$244(71.1) \quad 172(58.1) \quad 416(65.1)$

$99(28.9) \quad 124(41.9) \quad 223(34.9)$

$$
<0.001
$$

Age (years)

$\begin{array}{llll}15-19 & 40(11.7) & 51(17.2) & 91(14.2) \\ 20-24 & 173(50.4) & 151(51.0) & 324(50.7) \\ 25-40 & 130(37.9) & 94(31.8) & 224(35.1)\end{array}$

Encouragement to breastfeed was considered present if the woman had reported receiving encouragement or motivation to breastfeed from health workers, family members or relatives. Breastfeeding problem meant painful swelling of breast, and inverted, cracked or sore nipples affecting lactation.

In the presence of censoring observations due to lost to follow up or continuation of exclusive breastfeeding beyond the study period, Cox's proportional hazards modelling was used to assess the effect of residential location on the exclusive breastfeeding duration, accounting for plausible demographic and obstetric confounding variables. Both crude and adjusted hazards ratios (HR) and their $95 \%$ confidence intervals $(\mathrm{CI})$ were reported for each significant factor to estimate the corresponding risk of cessation of exclusive breastfeeding, and backward stepwise analysis was undertaken in view of the apparent collinearity between exposure variables. All statistical analyses were performed using the SPSS package version 21 .

\section{Results}

\section{Characteristics of participants}

Figure 1 shows the flow chart of the cohort. Of the initial 701 pregnant women recruited, 639 (91.2\%), 615 (87.7\%), and 515 (73.5\%) mothers were followed up at 4 weeks, 12 weeks, and 22 weeks after delivery, respectively. Table 1 presents the sample characteristics by residential location. About half of the mothers were primiparous $(51.5 \%)$ within the age group 20-24 years (50.7\%). The great majority of them were unemployed

${ }^{*}$ Chi-square test between urban and rural participants.

(1)


(79.7\%), and had normal delivery (86.6\%) at a health facility $(85.5 \%)$. Almost all pregnant women (98\%) had made at least one antenatal care visit. Most mothers reported receiving information about breastfeeding (73.6\%) and were encouraged to breastfeed by health personnel or family members (80.8\%), yet $35 \%$ of them experienced problems during lactation. Moreover, an examination using Spearman's rho indicated that certain variables were highly correlated, e.g. caste and education, age and parity. When comparing urban versus rural mothers, the two groups appeared to be significantly different in terms of employment, caste, education, place of delivery, method of delivery, availability of breastfeeding information, and presence of breastfeeding problem; see Table 1 . In particular, the prevalence of vaginal delivery was higher among rural women and more of them gave birth at home and received breastfeeding information relative to their urban counterparts.

\section{Exclusive breastfeeding rate and duration}

Table 2 summarises reported breastfeeding rates at birth, 4, 12 and 22 weeks. Although nearly all women (98\%) breastfed their infants up to six months, overall the exclusive breastfeeding rate declined from $90.9 \%$ at birth to $29.7 \%$ at 22 weeks. The main supplementary foods introduced were cow or buffalo milk while only a small proportion of the cohort (6\% to 13\%) fed their babies formula during the period. The data also indicated consistently higher rates of exclusive breastfeeding at birth and during follow up among rural mothers than urban mothers.

Of the 639 women in the cohort, 581 mothers fed colostrum to their infants at birth and 58 mothers gave other liquid as the first feed. This group of 581 women was eligible for survival analysis of exclusive breastfeeding duration. Kaplan-Meier log-rank test showed significant difference in exclusive breastfeeding between rural and urban women $(\mathrm{p}=0.02)$, with rural mothers (mean 144.7, 95\% CI 132.3 to 157.1 days) exclusively breastfed longer than urban mothers (mean 104.5, 95\% CI 95.8 to 113.1 days). Table 3 presents the result of stepwise Cox regression analysis, which confirm that urban women were more likely to cease exclusive breastfeeding (HR 1.28, $95 \%$ CI 1.03 to 1.60 ) after adjustment for confounders.
Other significant risk factors associated with the discontinuation of exclusive breastfeeding were reported breastfeeding problem (HR 2.07, 95\% CI 1.66 to 2.57) and caesarean delivery (HR 1.88, 95\% CI 1.36 to 2.62). The Kaplan-Meier curves corresponding to these three factors are shown in; see Additional file 3: Figure S1.

\section{Discussion}

Despite almost all mothers breastfed their infants during the six months follow up, only $30 \%$ reported exclusive breastfeeding at 22 weeks postpartum. Since about 20\% of the 639 participants were lost to follow up, the actual exclusive breastfeeding rate is likely to be lower. Breastfeeding is traditionally a common practice in Nepalese society, where most women have no salaried employment and are housewives, especially those residing in rural areas. Therefore, they have time to breastfeed their infants. Furthermore, women in the study district are highly aware of breastfeeding benefits, due to counselling during antenatal visits and after delivery [22]. Indeed, most women (74\%) made at least four antenatal visits while facility delivery was also high particularly among urban participants (91.5\%). Besides, support and encouragement can play an important role in breastfeeding duration [23-25]. About $80 \%$ of our mothers were encouraged to breastfeed by health workers or family members, which contributed to the reported high rate of breastfeeding in the study district.

The reported rate of exclusive breastfeeding declined substantially from birth to 22 weeks after delivery. Cow and/or buffalo milk is locally available and commonly regarded as alternative if breastmilk was perceived insufficient by the women. Moreover, in the Nepalese custom, almost all infants are likely to be introduced a solid food with a cultural ceremony called "pasni" by the end of six months, which might explain the decline in exclusive breastfeeding rates among both rural and urban mothers. In comparison, the recent NDHS reported that about 70\% of infants under six months of age are exclusively breastfed in Nepal [20], whereas an urban cross-sectional study found prevalence of exclusive breastfeeding of $74 \%, 24 \%$, and $9 \%$ at 1, 3, and 6 months, respectively [19]. The apparently higher rate from the NDHS survey might be caused by overestimation since the mothers' recall of feeding

Table 2 Breastfeeding status by residential location, Kaski district, Nepal, 2012

\begin{tabular}{|c|c|c|c|c|c|c|c|c|c|c|c|c|}
\hline \multirow[t]{3}{*}{ Breastfeeding } & \multicolumn{3}{|c|}{ At birth } & \multicolumn{3}{|c|}{4 weeks } & \multicolumn{3}{|c|}{12 weeks } & \multicolumn{3}{|c|}{22 weeks } \\
\hline & $\begin{array}{c}\text { Urban } \\
n=343\end{array}$ & $\begin{array}{c}\text { Rural } \\
n=296\end{array}$ & $\begin{array}{c}\text { Total } \\
\mathrm{n}=639\end{array}$ & $\begin{array}{c}\text { Urban } \\
n=343\end{array}$ & $\begin{array}{c}\text { Rural } \\
n=296\end{array}$ & $\begin{array}{c}\text { Total } \\
\mathrm{n}=639\end{array}$ & $\begin{array}{c}\text { Urban } \\
\mathrm{n}=\mathbf{3 1 9}\end{array}$ & $\begin{array}{c}\text { Rural } \\
n=296\end{array}$ & $\begin{array}{c}\text { Total } \\
n=615\end{array}$ & $\begin{array}{c}\text { Urban } \\
n=282\end{array}$ & $\begin{array}{c}\text { Rural } \\
n=233\end{array}$ & $\begin{array}{c}\text { Total } \\
n=515\end{array}$ \\
\hline & n (\%) & n (\%) & n (\%) & n (\%) & n (\%) & n (\%) & n (\%) & n (\%) & n (\%) & n (\%) & n (\%) & n (\%) \\
\hline Any & $\begin{array}{c}297 \\
(86.6)\end{array}$ & $\begin{array}{c}284 \\
(95.9)\end{array}$ & $\begin{array}{c}581 \\
(90.9)\end{array}$ & $\begin{array}{c}339 \\
(98.8)\end{array}$ & $\begin{array}{c}296 \\
(100.0)\end{array}$ & $\begin{array}{c}635 \\
(99.3)\end{array}$ & $\begin{array}{c}311 \\
(97.4)\end{array}$ & $\begin{array}{l}296 \\
(100)\end{array}$ & $\begin{array}{c}607 \\
(98.6)\end{array}$ & $\begin{array}{c}275 \\
(97.5)\end{array}$ & $\begin{array}{c}230 \\
(98.7)\end{array}$ & $\begin{array}{c}505 \\
(98.0)\end{array}$ \\
\hline Exclusive & $\begin{array}{c}297 \\
(86.6)\end{array}$ & $\begin{array}{c}284 \\
(95.9)\end{array}$ & $\begin{array}{c}581 \\
(90.9)\end{array}$ & $\begin{array}{c}280 \\
(81.6)\end{array}$ & $\begin{array}{c}259 \\
(87.5)\end{array}$ & $\begin{array}{c}539 \\
(84.4)\end{array}$ & $\begin{array}{c}201 \\
(63.0)\end{array}$ & $\begin{array}{c}212 \\
(71.6)\end{array}$ & $\begin{array}{c}413 \\
(67.2)\end{array}$ & $\begin{array}{c}76 \\
(26.9)\end{array}$ & $\begin{array}{c}77 \\
(33.0)\end{array}$ & $\begin{array}{c}153 \\
(29.7)\end{array}$ \\
\hline
\end{tabular}




\begin{tabular}{|c|c|c|c|}
\hline Factor & $\begin{array}{c}\text { Crude hazard } \\
\text { ratio } \\
(95 \% \mathrm{Cl})\end{array}$ & $\begin{array}{c}\text { Adjusted hazard } \\
\text { ratio* } \\
(95 \% \mathrm{Cl})\end{array}$ & $\mathrm{p}$ \\
\hline Residential location & & & 0.02 \\
\hline Rural & 1 & 1 & \\
\hline Urban & $1.21(0.98,1.49)$ & $1.28(1.03,1.60)$ & \\
\hline Method of delivery & & & $<0.001$ \\
\hline Vaginal & 1 & 1 & \\
\hline Caesarean & $2.12(1.54,2.93)$ & $1.88(1.36,2.62)$ & \\
\hline Breastfeeding problem & & & $<0.001$ \\
\hline No & 1 & 1 & \\
\hline Yes & $2.03(1.61,2.47)$ & $2.07(1.66,2.57)$ & \\
\hline
\end{tabular}

*Factors excluded from the backward stepwise Cox regression were maternal age, parity, employment status, caste, education, place of delivery, frequency of antenatal visits, breastfeeding information, encouragement to breastfeed, and sex of infant.

history was limited to the preceding 24 hours at the time of interview [26]. Globally, exclusive breastfeeding rate for infants under six months, based on national demographic survey data, ranged from $1 \%$ in Djibouti to $85 \%$ in Rwanda [8].

Exclusive breastfeeding also tends to vary within a country. In Nepal, the recent NDHS survey reported that the exclusive breastfeeding rate is higher among illiterate and poor women living in rural areas [20]. A study in Bangladesh similarly found that urban region, high maternal education and high socio-economic status were risk factors for the discontinuation of exclusive breastfeeding [27]. Another cohort study in China showed that more rural mothers exclusively breastfed than urban mothers [28]. In Nepal, urban women are more likely to be partially or fully employed, accessible to infant formula as well as exposed to their advertisements [17], which tend to have negative impact on exclusive breastfeeding. The finding of this study that urban women discontinued exclusive breastfeeding earlier than rural women adds to this line of evidence.

In this study, almost $40 \%$ of urban women did not report receiving breastfeeding information and their prevalence of caesarean section was higher than women residing in rural areas. Breastfeeding problem and caesarean delivery are well established risk factors for the cessation of exclusive breastfeeding [13,28,29]. Breastfeeding problems such as inverted, cracked or sore nipples can impact on the lactation decision and practice, while caesarean section can affect the secretion of breastmilk as well as the general health condition of the mother to exclusively breastfeed. In this study, exclusive breastfeeding duration was not associated with other demographic and obstetric factors including maternal age, education and parity.

\section{Limitations}

A major strength of the present study concerns the prospective assessment of breastfeeding practices from newly delivered women to minimise recall bias. However, all information obtained, including breastfeeding information and encouragement to breastfeed, was based on selfreport by the participants. The occurrence of some recall error on breastfeeding practices and duration during the personal interview could not be ruled out, especially for breastfeeding at birth which was asked about 4 weeks later. Despite feeding status was assessed at periodic intervals, the response might not represent the actual feeding practice throughout the whole 6-month period, because some women merely reported what they were feeding around the time of each interview. This study did not specifically capture whether water was given to the infant. Water was not generally considered as a food so that some participants might perceive they were feeding only breastmilk even though water was given occasionally.

Loss to follow up poses as another limitation. Due to time limit and budgetary constraint, the exact duration of exclusive breastfeeding could not be recorded for all infants and follow up of participants were conducted at periodic intervals without covering the full 6 months (approximately 4, 12 and 22 weeks postpartum). Finally, the findings may not be generalised to the whole country as Nepal is diversified in terms of ecology, ethnicity and social development. The Kaski district was ranked third in human development index out of 75 districts in Nepal with high adult literacy (82\%), and rural areas are connected to the central urban valley by gravelled roads [30].

\section{Conclusions}

Exclusive breastfeeding up to six months was more common in rural than urban areas of central Nepal. Despite the almost universal practice of breastfeeding, the reported exclusive breastfeeding rates declined substantially over time. Moreover, the duration of exclusive breastfeeding was found to be significantly associated with residential location, caesarean delivery and the presence of breastfeeding problem. Exclusive breastfeeding for at least six months should be encouraged, along with support, encouragement and the provision of comprehensive breastfeeding information to minimise potential problems during lactation, which would lessen the risk of early cessation of exclusive breastfeeding, especially for urban mothers.

\section{Additional files}

Additional file 1: STROBE Statement-Checklist of items that should be included in reports of cohort studies.

Additional file 2: Questionnaire: Infant feeding information and practices. Follow-up for infant feeding practices at 12 and 22 weeks after delivery. 
Additional file 3: Figure S1. Kaplan-Meier survival curves of cessation of exclusive breastfeeding by residential location, breastfeeding problem and delivery method, Kaski District, Nepal, 2012

\section{Competing interests}

The authors declare that they have no competing interests.

\section{Authors' contributions}

RK managed the project and coordinated data collection, performed statistical analysis and drafted the manuscript. AHL contributed to data analysis and revision of the manuscript. VK assisted with data collection and project development. CWB developed the study protocol and revised the manuscript. All four authors read and approved the final version for publication.

\section{Acknowledgements}

This study is part of the first author's PhD project at Curtin University supported by an Australian Awards Scholarship.

\section{Author details}

${ }^{1}$ School of Public Health and Community Medicine, BP Koirala Institute of Health Sciences, Dharan, Nepal. ${ }^{2}$ School of Public Health, Curtin University, GPO Box U1987, Perth, WA 6845, Australia. ${ }^{3}$ Sanjeevani College of Medical Sciences, Butwal, Rupandehi, Nepal.

Received: 1 February 2014 Accepted: 2 September 2014

Published: 8 September 2014

\section{References}

1. WHO, UNICEF: Planning Guide for National Implementation of the Global Strategy for Infant and Young Child Feeding. Geneva: World Health Organisation; 2007

2. WHO, UNICEF: Global Strategy for Infant and Young Child Feeding. Geneva: World Health Organisation; 2003.

3. Kramer MS, Aboud F, Mironova E, Vanilovich I, Platt RW, Matush L, Igumnov S, Fombonne E, Bogdanovich N, Ducruet T, Collet JP, Chalmers B, Hodnett E, Davidovsky S, Skugarevsky O, Trofimovich O, Kozlova L, Shapiro S: Breastfeeding and child cognitive development: new evidence from a large randomized trial. Arch Gen Psychiatry 2008, 65(5):578-584.

4. Lamberti L, Fischer Walker C, Noiman A, Victora C, Black R: Breastfeeding and the risk for diarrhea morbidity and mortality. BMC Public Health 2011, 11(3):1-12.

5. Kramer MS, Kakuma R: Optimal duration of exclusive breastfeeding. Cochrane Database Syst Rev 2012, 8, CD003517.

6. Black RE, Victora CG, Walker SP, Bhutta ZA, Christian P, De Onis M, Ezzati M, Grantham-Mcgregor S, Katz J, Martorell R, Uauy R: Maternal and child undernutrition and overweight in low-income and middle-income countries. Lancet 2013, 382(9890):427-451.

7. Horta B, Victora C: Long-term Effects of Breastfeeding: A Series of Systematic Reviews. Geneva: World Health Organisation; 2013.

8. Funds UNC's: The State of the World's Children 2014. New York: United Nations Children's Funds; 2014.

9. Gupta A, Dadhich JP, Suri S: How can global rates of exclusive breastfeeding for the first 6 months be enhanced? ICAN: Infant Child Adolesc Nutr 2013, 5(3):133-140.

10. Cai $X$, Wardlaw $T$, Brown D: Global trends in exclusive breastfeeding. Int Breastfeed J 2012, 7(1):12.

11. Binns C, Fraser M, Lee A, Scott J: Defining exclusive breastfeeding in Australia. J Paediatr Child Health 2009, 45(4):174-180.

12. Inoue M, Binns C, Otsuka K, Jimba M, Matsubara M: Infant feeding practices and breastfeeding duration in Japan: a review. Int Breastfeed J 2012, 7(1):15.

13. Scott JA, Binns CW, Oddy WH, Graham Kl: Predictors of breastfeeding duration: evidence from a cohort study. Pediatrics 2006, 117(4):e646-e655.

14. Bai Y, Middlestadt SE, Peng C-YJ, Fly AD: Predictors of continuation of exclusive breastfeeding for the first six months of life. J Hum Lact 2010, 26(1):26-34.

15. de Jager E, Skouteris H, Broadbent J, Amir L, Mellor K: Psychosocial correlates of exclusive breastfeeding: a systematic review. Midwifery 2013 29(5):506-518.
16. Mullany LC, Katz J, Li YM, Khatry SK, LeClerq SC, Darmstadt GL, Tielsch JM: Breast-feeding patterns, time to initiation, and mortality risk among newborns in Southern Nepal. J Nutr 2008, 138(3):599-603.

17. Pandey S, Tiwari K, Senarath U, Agho KE, Dibley MJ: Determinants of infant and young child feeding practices in Nepal: secondary data analysis of Demographic and Health Survey 2006. Food Nutr Bull 2010, 31(2):334-351.

18. Chandrashekhar TS, Joshi HS, Binu V, Shankar PR, Rana MS, Ramachandran U: Breast-feeding initiation and determinants of exclusive breast-feeding - a questionnaire survey in an urban population of western Nepal. Public Health Nutr 2007, 10(2):192-197.

19. Ulak M, Chandyo R, Mellander L, Shrestha P, Strand T: Infant feeding practices in Bhaktapur, Nepal: a cross-sectional, health facility based survey. Int Breastfeed J 2014, 7:1.

20. Ministry of Health and Population [Nepal], New ERA, ICF International Inc: Nepal Demographic and Health Survey 2011. Kathmandu, Nepal and Calverton, Maryland: Ministry of Health and Population [Nepal], New ERA, and ICF International Inc; 2012.

21. District Public Health Office Kaski: Annual Health Report of Kaski. Pokhara: Regional Health Directorate, Ministry of Health and Population, Government of Nepal; 2012.

22. Karkee $\mathrm{R}$, Lee $\mathrm{AH}$, Binns $\mathrm{CW}$ : Birth preparedness and skilled attendance at birth in Nepal: implications for achieving millennium development goal 5. Midwifery 2013, 29(10):1206-1210.

23. Duong DV, Binns CW, Lee AH: Breast-feeding initiation and exclusive breast-feeding in rural Vietnam. Public Health Nutr 2004, 7(06):795-799.

24. Tohotoa J, Maycock B, Hauck Y, Howat P, Burns S, Binns C: Dads make a difference: an exploratory study of paternal support for breastfeeding in Perth, Western Australia. Int Breastfeed J 2009, 4(1):15.

25. Mitchell-Box K, Braun KL, Hurwitz EL, Hayes DK: Breastfeeding attitudes: association between maternal and male partner attitudes and breastfeeding intent. Breastfeed Med 2013, 8(4):368-373.

26. Binns C, Lee A, Sauer K, Hewitt K: Reported breastfeeding rates in the Asia-Pacific Region. Curr Pediatr Rev 2012, 8(4):339-345.

27. Mihrshahi S, Kabir I, Roy SK, Agho KE, Senarath U, Dibley MJ: Determinants of infant and young child feeding practices in Bangladesh: secondary data analysis of Demographic and Health Survey 2004. Food Nutr Bull 2010, 31(2):295-313.

28. Qiu L, Zhao Y, Binns C, Lee A, Xie X: A cohort study of infant feeding practices in city, suburban and rural areas in Zhejiang Province, PR China. Int Breastfeed J 2008, 3(1):4

29. Bouras G, Mexi-Bourna P, Bournas N, Christodoulou C, Daskalaki A, Tasiopoulou I, Poulios A: Mothers' expectations and other factors affecting breastfeeding at six months in Greece. J Child Health Care 2013, 17(4):387-396.

30. Central Bureau of Statistics: National Population and Housing Census 2011. Kathmandu: National Planning Commission Secretariat, Central Bureau of Statistics, Government of Nepal; 2012.

doi:10.1186/1471-2458-14-927

Cite this article as: Karkee et al:: A community-based prospective cohort study of exclusive breastfeeding in central Nepal. BMC Public Health 2014 14:927.

\section{Submit your next manuscript to BioMed Central and take full advantage of:}

- Convenient online submission

- Thorough peer review

- No space constraints or color figure charges

- Immediate publication on acceptance

- Inclusion in PubMed, CAS, Scopus and Google Scholar

- Research which is freely available for redistribution 